\title{
Juvenile rheumatoid arthritis and del(22q11) syndrome: a non-random association
}

\author{
Alain Verloes, Cynthia Curry, Mauricette Jamar, Christian Herens, Patricia O'Lague, \\ James Marks, Pierre Sarda, Patricia Blanchet
}

Wallonia Centre for Human Genetics, Liège University, CHU Sart Tilman, B-4000 Liège, Belgium

A Verloes

M Jamar

C Herens

\section{Medical}

Genetics/Prenatal Detection Unit, Valley Children's Hospital,

University of

California San

Francisco, Fresno, USA

C Curry

P O'Lague

J Marks

Department of Medical Genetics, University Hospital Arnaud de Villeneuve, Montpellier, France P Sarda

P Blanchet

\section{Correspondence to:}

Dr Verloes.

\begin{abstract}
Del(22q11) is a common microdeletion syndrome with an extremely variable phenotype. Besides classical manifestations, such as velocardiofacial (Shprintzen) or DiGeorge syndromes, del(22q11) syndrome may be associated with unusual but probably causally related anomalies that expand its phenotype and complicate its recognition. We report here three children with the deletion and a chronic, erosive polyarthritis resembling idiopathic cases of juvenile rheumatoid arthritis (JRA).
\end{abstract}

Patient 1 , born in 1983, initially presented with developmental delay, facial dysmorphism, velopharyngeal insufficiency, and severe gastro-oesophageal reflux requiring $G$ tube feeding. From the age of 3 years, he developed JRA, which resulted in severe restrictive joint disease, osteopenia, and platyspondyly. Patient 2, born in 1976, had tetralogy of Fallot and peripheral pulmonary artery stenosis. She developed slowly, had mild dysmorphic facial features, an abnormal voice, and borderline intelligence. JRA was diagnosed at the age of 5 years. The disorder followed a subacute course, with relatively mild inflammatory phenomena, but an extremely severe skeletal involvement with major osteopenia, restrictive joint disease (bilateral hip replacement), and almost complete osteolysis of the carpal and tarsal bones with phalangeal synostoses, leading to major motor impairment and confinement to a wheelchair. Patient 3 , born in 1990, has VSD, right embryotoxon, bifid uvula, and facial dysmorphism. She developed JRA at the age of 1 year. She is not mentally retarded but has major speech delay secondary to congenital deafness inherited from her mother.

In the three patients, a $\operatorname{del}(22 q 11)$ was shown by FISH analysis. These observations, and five other recently published cases, indicate that a JRA-like syndrome is a component of the del(22q11) spectrum. The deletion may be overlooked in those children with severe, chronic inflammatory disorder.

( $\mathcal{}$ Med Genet 1998;35:943-947)

Keywords: juvenile rheumatoid arthritis; del(22q11) syndrome

Del(22q11) syndrome is a newly recognised contiguous gene syndrome resulting from a (usually) submicroscopic deletion in the proxi- mal part of the long arm of chromosome 22, encompassing in its phenotype Shprintzen velocardiofacial syndrome, ${ }^{1}$ Takao conotruncal anomalies face syndrome, DiGeorge anomaly, ${ }^{2}$ some instances of Opitz GBBB syndrome type $2,{ }^{3}$ and isolated outflow tract defects (such as truncus arteriosus, tetralogy of Fallot, or interrupted aortic arch). The incidence could be as high as $1 / 3500$ births.

The spectrum of clinical anomalies associated with 22q11 monosomy is remarkably variable. Recently, juvenile rheumatoid arthritis (JRA) has been reported in association with $\operatorname{del}(22 \mathrm{q} 11)$ in five children. ${ }^{45}$ We report here three further cases of this association, indicating that the presence of a JRA-like disorder may not be fortuitous, but rather causally related to the presence of the deletion.

\section{Case reports}

PATIENT 1

This girl is the second child of unrelated parents, born after an uneventful pregnancy. Clinical investigations at birth showed a tetralogy of Fallot, which was partially surgically corrected at the age of 10 months, pulmonary valvular insufficiency, and peripheral pulmonary stenosis. No other malformations were present. Assessment of calcium metabolism and immunodeficiency are not available from that time, but suspicion of DiGeorge syndrome was never raised in her medical records.

At the age of 4 years (fig 1A), she was admitted for painful inflammatory swelling of the knees, for which she was treated with indomethacin and salicylates. Sedimentation ratio was repeatedly high. There was no hepatosplenomegaly. Calcium homeostasis, serum parathormone and thyrocalcitonin, and lymphocyte counts were normal. The clinical course was notable for multiple relapses of the arthritis during the next 15 years, affecting all large and small joints, usually with an important inflammatory component but no fever ("subacute" JRA). Therapy was initially limited to antiinflammatory drugs. Corticosteroids were used from 9 to 18 years and d-penicillamine from 12 to 14 years. There were no ocular manifestations of iridocyclitis or uveitis. At the age of 12, transient non-viral hepatitis was noted. Progressive right ventricular insufficiency was treated with digitalis. Despite corticoids, progressive destruction of the hips and knees led her to become wheelchair bound. Because of progressive flexion deformity, she required tenotomies around the hips and knees at the age of 15 . At the age of 20, hip replacement was performed. There was major involvement of the hands and 

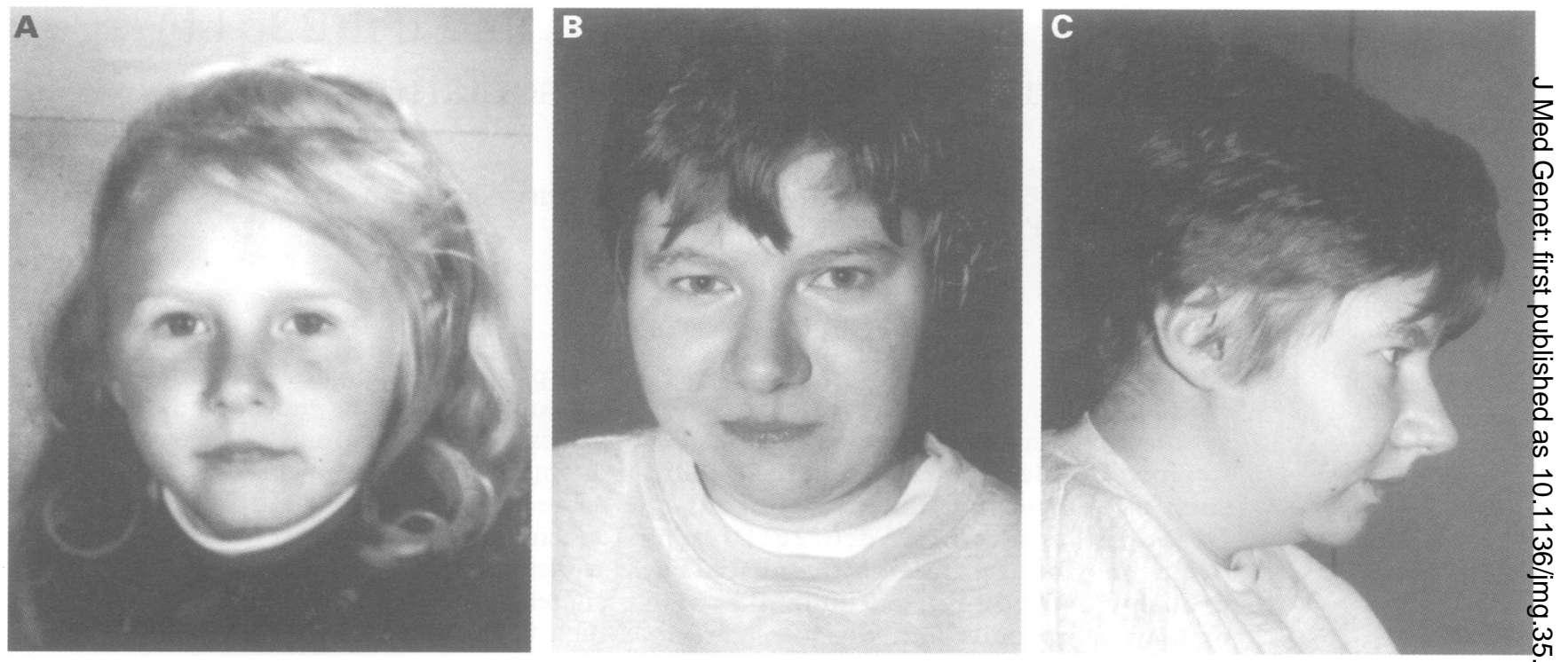

Figure 1 Patient 1. (A) Front view in infancy. $(B, C)$ Appearance at the age of 22: note prominent nose with large tip and narrow palpebral fissures.

wrists. Immune investigations repeatedly showed hypergammaglobulinaemia, circulating IgA immune complexes, and absence of rheumatoid factor, anti-DNA antibodies, and antinuclear antibodies. HLA typing was A3A9B35-DR1DR5.

When we saw her at the age of 22 , she was non-ambulatory. Ankylosis of the elbows and finger retraction severely restricted her ability in fine motor skills. She was of apparently low normal intelligence. She had a large nose, narrow palpebral fissures, narrow mouth (fig 1B, C), and high palate. She had a high pitched, nasal voice. IQ testing was not performed. A skeletal survey showed kyphoscoliosis, generalised arthropathy (including the sacroiliac joints), severe osteopenia, carpal osteolysis, and secondary synostosis of the metacarpals and phalanges (fig 2). She had attended normal school until the age of 10 and was switched thereafter to special schooling. Poor academic achievement was attributed to her physical problems.

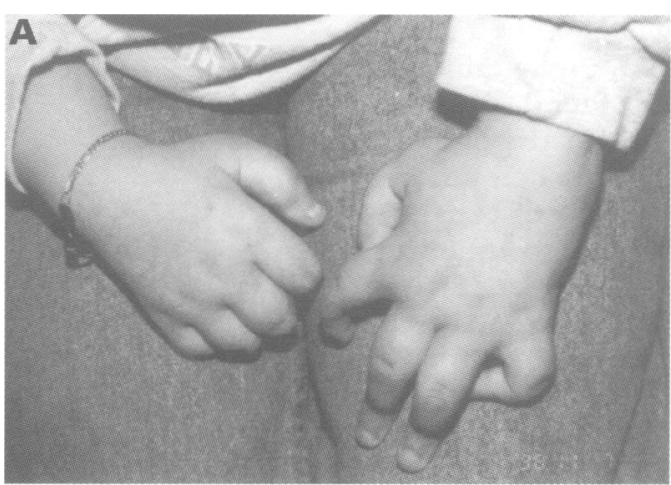

$\operatorname{Del}(22 q 11)$ was shown on spread chromosomes hybridised with the specific DNA probeo D22S75 and the control probe D22S39. (Oncor), using standard FISH techniques, as recommended by the manufacturer.

The mother suffered recurrent psychiatric $\stackrel{\mathbb{S}}{=}$ problems and had abandoned her daughtero during infancy. Features noted in familyphotographs suggest that she probably also hade the deletion. None of the relatives had ankylos-ing spondylitis, inflammatory bowel disease,, uveitis, psoriasis, or psoriatic arthritis (and the same is true for the other two cases).

PATIENT 2

This boy is the second child of healthy, $\overrightarrow{\overline{0}}$ unrelated parents. His neonatal course was characterised by low birth weight, hypotonia, and poor feeding. Language development was delayed. Clinical examination at the age of 2 years showed a coarse, expressionless ${ }_{0}^{\circ}$ ("myopathic") face (fig 3A), brachycephaly with normal OFC, flat nasal bridge,

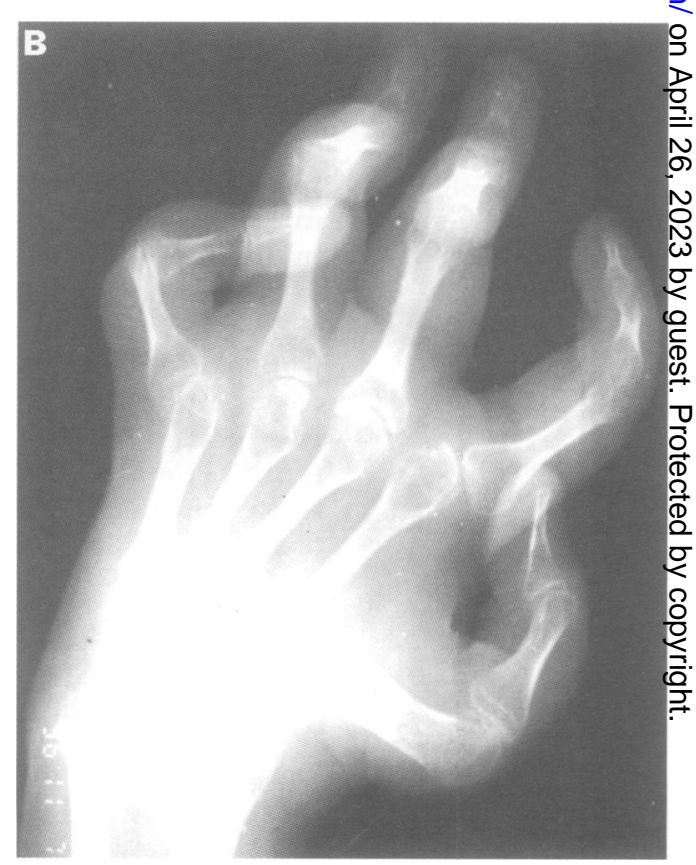



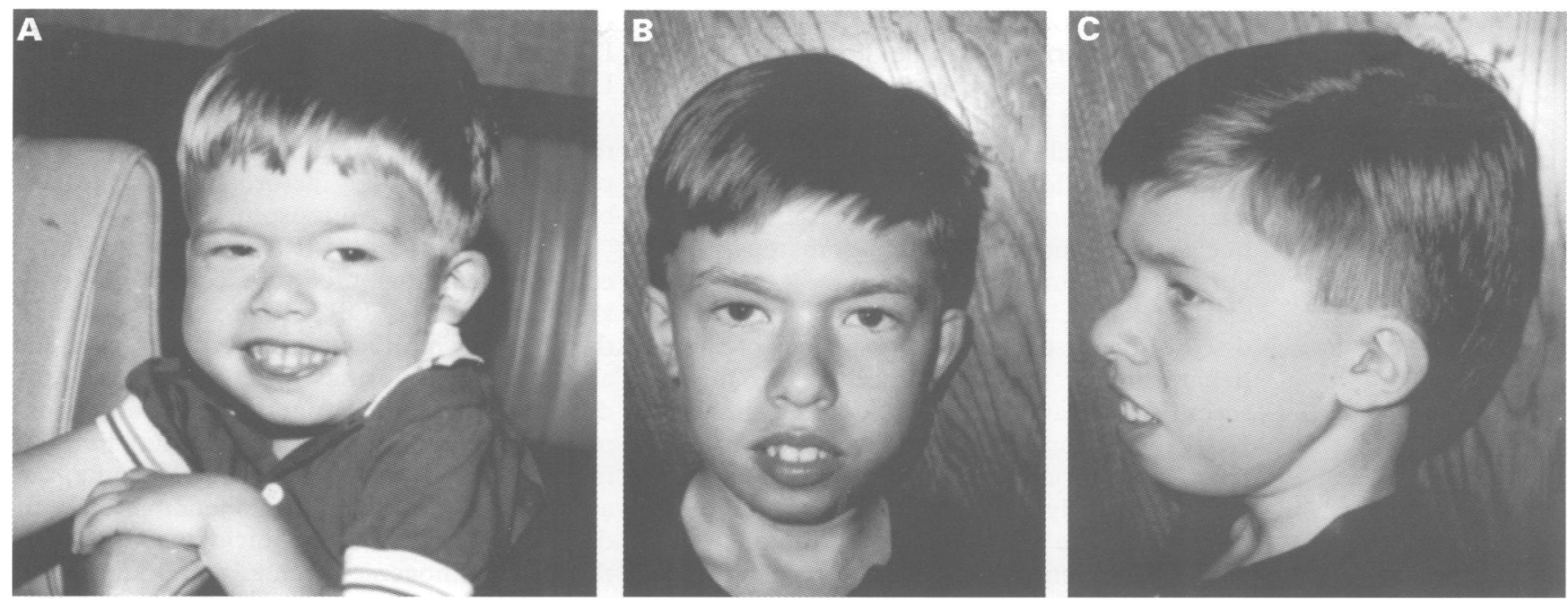

Figure 3 Patient 2. (A) Front view in infancy. $(B, C)$ Appearance at the age of 12: note prominent nose with large tip and narrow palpebral fissures.

micrognathia, thick helices, short neck, tapering fingers, and transverse palmar creases. $X$ rays showed delayed bone maturation, osteoporosis, and mild platyspondyly. Scans of the heart and head were normal. Later, velopharyngeal insufficiency (without cleft) failed to respond to intensive speech therapy. He had severe gastrooesophageal reflux that necessitated gastrostomy feeding from the ages of 5 to 13 . He suffered from chronic constipation and was of short stature ( $<3$ rd centile). His full scale IQ was estimated at 58 at the age of 14 . Fig $3 \mathrm{~B}$ and $\mathrm{C}$ show his clinical appearance at the age of 12 .

JRA was diagnosed at the age of 3 . The severe course of the disease required treatment with gold, Plaquenil, and methotrexate. At the age of 16 , he has severe chronic restrictive joint disease involving the hips, wrists, fingers, and temporomandibular joints. He had had low lymphocyte counts in infancy, but later $\mathrm{T}$ and $B$ cell counts were normal. Immunological investigations showed absence of antinuclear antibodies and rheumatoid factor. Immunoglobulin levels were usually normal. CD3, CD4, and CD8 lymphocyte counts were normal, as was the helper/suppressor ratio. Hypocalcaemia was never observed. HLA typing was A1A2-B8B44-CW5CW7-DR4DR17DRW52DRW53-DQ2DQ3.

Finally, in 1996, karyotyping with probe D22S75 (Oncor) showed a 22q11 deletion.

\section{PATIENT 3}

This child, born in 1990, was the first girl of unrelated French parents. The mother suffered congenital unilateral deafness. Birth weight was $2670 \mathrm{~g}$, length $46 \mathrm{~cm}$, and OFC $34 \mathrm{~cm}$. Clinical investigations at birth showed VSD and camptodactyly of the toes. There were no feeding problems during the first year of life and psychomotor development was not delayed. Severe bilateral deafness was diagnosed at 9 months. At the age of 1 year, she presented with acute polyarthritis affecting large and small joints with mildly increased CRP. JRA was diagnosed and required salycilate and later corticosteroid treatment. She later attended a school for deaf children. She was considered to be of normal intelligence.
When first evaluated aged 7, several dysmorphic features were noted: ridged metopic suture, narrow, upward slanting palpebral fissures, large nose with bulbous tip, small mouth, high vaulted palate with bifid uvula, crowded teeth, small ears, and right posterior embryotoxon. She showed painful ankylosis of the wrists, elbows, ankles, knees, fingers, and toes, with secondary retractions of the small joints. Calcium homeostasis, circulating vitamin A, and PTH were normal. $X$ rays showed osteopenia (confirmed by osteodensitometry) and generalised JRA arthropathy. Immunological investigations showed normal lymphocyte count and the absence of rheumatoid factor and anti-DNA and antinuclear antibodies. CD3, CD4, CD8, and helper/suppressor ratio were in the normal range. HLA genotype was A2A3-B13B62-CW6-DR13-DQ6.

Karyotyping with probe D22S75 (Oncor) showed a 22q11 deletion. The mother was not deleted; the father was not tested.

\section{Discussion}

$\operatorname{Del}(22 q 11)$ is a multiple congenital anomaly (MCA) syndrome, with a remarkably variable and continually expanding phenotype ${ }^{6-10}$ that merges Shprintzen velocardiofacial syndrome, most cases of DiGeorge sequence, ${ }^{11}$ some cases of Robin sequence, and rare, often atypical instances of the CHARGE association. Although phenotypic expression of the disorder has become increasingly better recognised, relatively few data have been recorded on immune dysfunction beyond the neonatal period, during which manifestations of DiGeorge syndrome (with thymic hypoplasia and immunodeficiency) may be observed in roughly $10 \%$ of cases. In older children, little or absent lymphoid tissue has been documented in a majority of cases. ${ }^{12} \mathrm{~T}$ cell dysfunction has been observed in the milder cases of DiGeorge syndrome. ${ }^{13} 14$

Some case reports mention autoimmune disorders in the syndromes known to belong to the del(22q11) spectrum. A single older patient with DiGeorge syndrome has been reported with autoimmune Graves disease. ${ }^{15}$ Two adults with del(22q11) were recently reported with adult onset idiopathic thrombocytopenia 
associated in one case with chronic leucopenia. ${ }^{16}$ A similar pattern of infantile thrombocytopenia followed by haemolytic anaemia at the age of 8 was mentioned in an abstract. ${ }^{17}$ In the report of Pinchas-Hamiel et $a l{ }^{18}$ a child with DiGeorge syndrome suffered autoimmune haemolytic anaemia (responding to corticosteroids), thrombocytopenia, and chronic, granulomatous, probably autoimmune hepatitis.

The exact classification of the rheumatoid disease in our cases was the subject of much debate during the preparation of this manuscript. American authors (who prefer the term JRA) and European authors (who often use the term "juvenile chronic arthritis (JCA)") appear to have slightly different definitions of these disorders. The most recently adopted international nomenclature uses the term juvenile idiopathic arthritis (JIA). Whatever name is chosen (JRA, JCA, or JIA), it requires that the arthritis is idiopathic, that is, not associated with any other recognisable condition. As, before the discovery of the microdeletion, the three patients were considered to have bona fide JRA by several rheumatologists in the three university hospitals where they were followed, and as a causal relationship with $\operatorname{del}(22 \mathrm{q} 11)$ has still to be proven, we suggest that the erosive polyarthritis observed in association with del(22q11) should be described as a JRAlike disorder. Synovial puncture was not performed, so we have no idea of the cytological appearance of the articular fluid.

A JRA-like disorder has been reported in five children with $\operatorname{del}(22 \mathrm{q} 11) .^{45}$ In the report of Rasmussen et $a l,{ }^{4}$ onset was at 7 and 6 years, respectively. Both had positive antinuclear antibodies and one of them was positive for rheumatoid factor. HLA typing was not performed (S Rasmussen, personal communication). Interestingly, case 2 of Rasmussen et $\mathrm{l}^{4}$ inherited the deletion from her father and had two deleted sibs: neither of them developed JRA. In the report of Sullivan et al, ${ }^{5}$ two boys and one girl were described with JRA and $\operatorname{del}(22 q 11)$. Onset was at 17 months, 19 months, and 5 years, respectively. One had positive antinuclear antibodies and all were negative for rheumatoid factor. They each had two HLA alleles associated with an increased risk of polyarticular JRA. The three children showed immunological anomalies: all three had impaired response to mitogens, two had IgA deficiency, the two youngest patients had abnormal CD 4:CD8 $\mathrm{T}$ cell ratio, and the third one an increased ratio. In each case, as in our patients, the course was "subacute", polyarticular and there were no ocular complications nor systemic features such as rash, organomegaly, or lymphadenopathy and, apparently, only mild increase of inflammatory markers.

JRA is a common autoimmune disease of childhood. Its incidence is about 1/10 000 and its prevalence $1 / 1000$. Although most cases are sporadic, many multiplex pedigrees have been observed in which JRA shows familial aggregation compatible with partially penetrant autosomal dominant inheritance. ${ }^{19}{ }^{20}$ One third to one half of the familial transmission is accounted for by linkage to the HLA $\operatorname{loci}^{2122}$ with predisposing alleles such as DR5, DR8, DP2.1, DRB1 (particularly DRB1*0401), and DQB1, whereas linkage to DR1 or DR4, oftefr observed in adult onset rheumatoid arthritis, rarely noted in the paediatric population wit? positive rheumatoid factor. No linkage ha been shown with chromosome 22 .

The pathogenesis of JRA is complex, ${ }^{21}$ but central role is attributed to $\mathrm{T}$ cells, as the onl known function of DR is to present peptides $t$ the CD4 T lymphocytes. Abnormal suppresso activity and abnormal immunoglobulin pros duction are part of JRA and point to an abnore mal $\mathrm{T}$ cell function. ${ }^{23}$ As $\mathrm{T}$ cell dysfunction is major component of DiGeorge syndrome, the association of autoimmune phenomenon with del(22q11) may not be coincidental, although the exact pathogenic mechanism remains to be solved. Rasmussen $e t$ al $l^{4}$ noted that in their two families other members had joint problemsis They speculated that JRA could occur for genetic reasons unrelated to the $\operatorname{del}(22 q 11)$ We would rather suggest that JRA is pathogenif cally related to del(22q11), the $T$ cell dysfunce tion component of DiGeorge sequence being a possible adjuvant for developing JRA in those who have other predisposing factors (such as specific HLA subtypes). Exact DR typing ot JRA positive del(22q11) cases is not available in all cases, but in our case 1 , as in that of Sullivan et $a l^{5}$ the expected DR1 group waso present.

$\operatorname{Del}(22 q 11)$ syndrome is currently consido ered to be a contiguous gene syndrome. The deletion usually spans $3 \mathrm{Mb}$, but some patient have much smaller, nested deletions. The critio cal region is about $480 \mathrm{~kb}$ in size. ${ }^{24}$ The differ ence in deletion size or modifying genetic loci o $\overline{\overline{0}}$ both may account for a part of the diversity of expression of the disorder, but the genomic basis of $\operatorname{del}(22 q 11)$ syndrome is still unknown:Six genes and several unidentified ESTs have been mapped in the critical region. ${ }^{25}$ These include the clathrin heavy chain gene CLTD, GSCL, a goosecoid-like homeobox gene ex? pressed in early human development, ${ }^{27}$ the mitochondrial citrate transport protein $\mathrm{CTP},{ }^{28}$ HIRA, a protein related to yeast repressors of histone transcription genes, ${ }^{29}$ and TMVCF, transmembrane protein of unknown function. Other genes have been mapped within the larger deletion, but outside the critical region: TUPLE1, a putative transcription factor, ${ }^{20 \omega}$ ZNF74, a zinc finger gene, ${ }^{31}$ a homologue Drosophila dishevelled gene, ${ }^{32}$ DGCR6, a gene with homologies to Drosophila gonadal proteiro gdl, the $\gamma 1$ chain of human laminin, ${ }^{33} \mathrm{~T} 10, \mathfrak{a}^{9}$ sequence expressed during embryonic develop ment, ${ }^{34}$ and several other less well defined genes (DGCR5, rpL28, ARV, and V1-41 ${ }^{25}$ ). None of these genes appears to play an important role irp $\mathrm{T}$ cell immunity.

The incidence of JRA in $\operatorname{del}(22 q 11)$ if unknown. Sullivan et aĺ gave an estimate of $4 \%$ for their local series of cases, but JRA has neves been mentioned in older reviews on DiGeorget or VCF syndrome, and is not mentioned in the recent collaborative European study. ${ }^{10}$ This could be an indication of the rarity of this complication, but we feel it is more likely that the 
severe complications of JRA may obscure the classical phenotype of $\operatorname{del}(22 \mathrm{q} 11)$ and prevent its recognition. The incidence of $\operatorname{del}(22 q 11)$ among JRA patients is completely unknown. Short stature and failure to thrive, which are associated with del(22q11) syndrome, can be attributed to JRA. Facial anomalies in $\operatorname{del}(22 \mathrm{q} 11)$ are quite subtle and can be blurred by the effects of corticotherapy. It is likely that the long periods of illness and their interference with normal schooling may be considered to be responsible for school difficulties, behavioural problems, and mild intellectual impairment. For these reasons, referral for clinical genetic evaluation is probably infrequent so that $\operatorname{del}(22 q 11)$ is more likely to be missed in this population of children.

We would strongly recommend careful reevaluation of all children with JRA who show velopharyngeal insufficiency, learning disabilities, or heart anomalies for possible $22 \mathrm{q} 11$ deletion. In reviewing papers reporting chronic arthritis with multisystemic involvement, we wonder whether some cases may have $\operatorname{del}(22 \mathrm{q} 11)$. This could certainly be the case for patients 2 and 3 in a "new" syndrome reported by Coffin, ${ }^{35}$ consisting of mental retardation, arthritis, deafness, and facial dysmorphism. Chronic, infantile, neurological, cutaneous, and articular (CINCA) syndrome (Lorber syndrome) designates series of isolated patients reported with polyarthritis, developmental problems, failure to thrive, and hearing loss. ${ }^{36}$ Some of them could have del(22q11). In an ill defined syndrome labelled camptodactyly-arthritis, ${ }^{37}$ some patients may also have the deletion.

1 Kelly D, Goldberg R, Wilson D, et al. Confirmation that the velo-cardio-facial syndrome is associated with haploinsufficiency of genes at chromosome $21 \mathrm{q} 11 . \mathrm{Am} \mathcal{F} \mathrm{Med}$ Genet 1993;45:308-12.

2 Scambler PJ, Kelly D, Lindsay E, et al. Velo-cardio-facia syndrome associated with chromosome 2 deletions encompassing the DiGeorge locus. Lancet 1992;339:1138-9.

3 McDonald-McGinn DM, Driscoll DA, Bason L, et al. Autosomal dominant "Opitz" GBBB syndrome due to a 22q11.2 deletion. Am 7 Med Genet 1995;59:103-13.

4 Rasmussen SA, Williams CA, Ayoub EM, et al. Juvenile rheumatoid arthritis in velo-cardio-facial syndrome; coincidence or unusual complication? Am f Med Genet 1996;64: 546-50.

5 Sullivan KE, McDonald-McGinn DM, Driscoll DA, et al. Juvenile rheumatoid arthritis-like polyarthritis in chromosome 22q11.2 deletion syndrome (DiGeorge anomalad/ velocardiofacial syndrome/conotruncal anomaly face syndrome). Arthritis Rheum 1997;40:430-6.

6 Goldberg R, Motzkin B, Marion R, Scambler PJ, Shprintzen RJ. Velo-cardio-facial syndrome: a review of 120 patients. Am $₹$ Med Genet 1993;45:313-19.

7 Leana-Cox J, Pangkanon S, Eanet KR, Curtin M, Wulsberg EA. Familial DiGeorge/velocardiofacial syndrome with deletions of chromosome area 22q11.2: report of five families with a review of the literature. $A m \mathcal{F}$ Med Genet 1996;65:309-15.

8 Ravnan JB, Chen E, Golabi M, Lebo RV. Chromosome 22q11.2 microdeletions in velocardiofacial syndrome patients with widely variable manifestations. $\mathrm{Am} \mathcal{f} \mathrm{Med}$ Genet 1996;66:250-6.

9 Wulfsberg EA, Leana-Cox J, Neri G. What's in a name? Chromosome 22q abnormalities and the DiGeorge, velocardiofacial, and conotruncal anomalies face syndromes. Am $\mathcal{F}$ Med Genet 1996;65:317-19.

10 Ryan AK, Goodship JA, Wilson DI, et al. Spectrum of clinical features associated with interstitial chromosome 22q11 deletions: a European collaborative study. $7 \mathrm{Med}$ Genet 1997;34:798-804.
11 Stevens CA, Carey JC, Shigeoka AO. DiGeorge anomaly and velocardiofacial syndrome. Pediatrics 1990;85:526-9.

12 Williams MA, Shprintzen RJ, Rakoff SJ. Adenoid hypoplasia in the velo-cardio-facial syndrome. $\mathcal{F}$ Craniofac Genet Dev Biol 1987; 7:23-6.

13 Durandy A, Le Deist F, Fischer A, Griscelli C. Impaired T8 lymphocyte-mediated suppressive activity in patients with partial DiGeorge syndrome. 7 Clin Immunol 1986;6:26570 .

14 Müller W, Peter HH, Kallfelz HC, Franz A, Rieger CHL The DiGeorge sequence. II. Immunologic findings in partial and complete forms of the disorder. Eur $\mathcal{F}$ Pediatr 1989 149:96-103.

15 Pong AJ, Cavallo A, Molman GM, Goldman AS. DiGeorge syndrome: long-term survival complicated with Graves disease. F Pediatr 1985;106:619-20.

16 Lévy A, Michel G, Le Merrer M, Philip N. Idiopathic thrombocytopenic purpura in two mothers of children with DiGeorge sequence: a new component manifestation of deletion 22q11. Am 7 Med Genet 1997;69:356-9.

17 Sherry RM, Nelson RP, Good RA. Association of immune thrombocytopenia and autoimmune hemolytic anemia in DiGeorge syndrome. Pediatric Res 1990;27:62A.

18 Pinchas-Hamiel O, Mandel M, Engelberg S, Passwell JH. Immune hemolytic anemia, thrombocytopenia and liver disease in a patient with DiGeorge syndrome. Isr $\mathcal{F} \mathrm{Med} S \mathrm{Si}$ 1994;30:530-2.

19 Lynn AH, Kwoh CK, Venglish CM, Aston CE, Chakravarti A. Genetic epidemiology of rheumatoid arthritis. $\mathrm{Am} \mathcal{F}$ Hum Genet 1995;57:150-9.

20 Hasstedt SJ, Clegg DO, Ingles L, Ward RH. HLA-linked rheumatoid arthritis. Am $\mathcal{F}$ Hum Genet 1994; 55:738-46.

21 Feldmann M, Brennan FM, Maini RN. Rheumatoid arthritis. Cell 1996;85:307-10.

22 Vyse TJ, Todd JA. Genetic analysis of autoimmune disease. Cell 1996;85:311-18.

23 Lipnick RN, Tsokos GC. Immune anomalies in the pathogenesis of juvenile rheumatoid arthritis. Clin Exp Rheumatol 1990;8:177-86.

24 Carlson C, Sirotkin H, Pandita R, et al. Molecular definition of 22q11 deletions in 151 velo-cardio-facial syndrome patients. Am ₹ Hum Genet 1997;61:220-9.

25 Carlson CG, Sirotkin H, Pandita R, et al. Definition of deletions within a $10 \mathrm{~kb}$ resolution physical and transcription map of the 22q11 region associated with velo-cardio-facial syndrome. Am F Hum Genet Suppl 1996;59:A214.

26 Sirotkin H, Morrow B, Das Gupta R, et al. Isolation of a new clathrin heavy chain gene with muscle-specific expression from the region commonly deleted in the velo-cardio-facial syndrome. Hum Mol Genet 1996;5:61 7-24.

27 Gottlieb S, Emanuel BS, Driscoll DA, et al. The DiGeorge syndrome minimal critical region contains a Goosecoidlike homeobox gene that is expressed in early human development. Am f Hum Genet 1997;60:1194-201.

28 Hiesterkamp N, Mulder MP, Langeveld A, et al. Localization of the human mitochondrial citrate transporter protein gene to chromosome 22q11 in the DiGeorge syndrome critical region. Genomics 1995;29:451-6.

29 Halford S, Wadey R, Roberts C, et al. Isolation of a putative transcriptional regulator from the region of $22 \mathrm{q} 11$ deleted in DiGeorge syndrome, Shprintzen syndrome and familial congenital heart disease. Hum Mol Genet 1993;12:2099117 .

30 Sirotkin H, Morrow B, Saint-Jore B, et al. Identification and characterization of a novel membrane spanning gene from the region commonly deleted in velo-cardio-facial syndrome. Genomics 1997;42:245-51.

31 Aubry M, Demczuk S, Desmaze C, et al. Isolation of a zinc finger gene consistently deleted in DiGeorge syndrome. Hum Mol Genet 1993;2:1583-7.

32 Pizzuti A, Novelli G, Mari A, et al. Human homolog sequences to the Drosophila dishevelled segment-polarity gene are deleted in the DiGeorge syndrome. Am f Hum Genet 1996;58:722-9.

33 Demczuk S, Thomas G, Aurias A. Isolation of a novel gene from the DiGeorge critical region with homology to Drosophila gdl and to human LAMC1 genes. Hum Mol Genet 1996;5:633-8.

34 Halford S, Wilson DI, Daw SCM, et al. Isolation of a gene expressed during early embryogenesis from a region of 22 q11 commonly deleted in DiGeorge syndrome. Hum Mol Genet 1993;2:1577-82.

35 Coffin GS. Developmental retardation with unusual facies, arthritis, and hearing impairment. Dysmorphol Clin Genet 1990;4:103-9.

36 Prieur AM, Griscelli C, Lampert F. A chronic, infantile, neurological, cutaneous and articular (CINCA) syndrome. A specific entity analysed in 30 patients. Scand $\mathcal{F}$ Rheumatol 1987;suppl 66:57-68.

37 Malleson P, Schaller JG, Dega F. Familial arthritis and camptodactyly. Arthritis Rheum 1981;24:1199-204. 